A double dose of the quantity of peletierin, tr. jalap and castor oil, as above stated, was administered, when several ( 7 or 8 feet) more feet of the worm was dislodged, including the head, which he then exhibited to the society.

Dr. Doering stated that he had treated three children having tænia, one of which was 9 years old, another 4 years of age, and a baby that was but 6 months old. The last case had been fed on raw beef whilst being sick with entero-colitis. $\mathrm{He}$ was surprised to hear of Dr. Davis' success with the remedies he had used, given in such small quantities, as he had himself practiced the same method of treatment and with larger doses of the peletierin, with but partial success only.

Hygroma Linguce.-Under somewhat of a disadvantage $D r$. Josef Zeisler reported a congenital case of this rare disease, or bearing this title, which is under his care. Said he: It is a strange disease of the tongue that has occurred to Emma L., who is now about 9 years old. She has suffered from the trouble since her birth. The child is well nourished, but her complexion is pale. Her face is asymmetrical to a considerable degree, and its formation is very incommensurable in a number of respects. The right half of her face is much more developed in its muscular and osseous formation than its opposite side. No swollen submaxillary or cervical glands are present. Her tongue was described as having the following appearance: It is much thickened, the surface appears to consist of small vesicles or cysts, varying in size from a pinhead to that of a pea, lying by the side of each other in the form of mosaic pieces of work, or in a tessellated shape. These cysts seem to contain a colloid mass, and this condition affects the entire visible portion of the tongue, so that no intact mucous membrane can be seen. Over the middle of the tongue there extends a kind of cockscomb or carunculated excrescence, or cristate in form, of the same appearance, but presenting a more papillary or warty resemblance. These crists are also found on the mucous membrane of the right cheek near the angle of the mouth. In handling or touching the tongue, the surface imparts a sensation as if it consisted of oil-globules or boiled sago. The movements of the organ, as well as speech, are not impeded, nor is the sense of taste in the least impaired. There are no spontaneous pains proceeding from it, and pain arises only when strong compression is made upon her tongue, or, as the child says, when acid substances are taken. Relatives of the child report that its tongue was formerly much larger, although it sometimes now appears to become oedematous and then grow smaller again. Her parents and her five brothers and sisters have always enjoyed good health and are in a healthy condition at the present time.

The writer regards this disease from a pathological standpoint as a colloid degeneration of the mucous membrane of the tongue, but he could not classify it clinically, having never seen a similar case previously. A microscopical examination was not permitted to be made of any of the cysts or their contents. Galvanopuncture was suggested as a remedy, which was also declined. Dr. E. Andrews, Dr. C. T. Parkes, Dr. J. N. Hyde, and several other well-known physicians had seen this case, but could add nothing further of interest relative to it, nor to the treatment. They had neither of them seen a similar case. Dr. Doering had seen this patient two years ago. The tongue then presented a "sago pudding" appearance, and he presumed it still retained the same features. $\mathrm{He}$ further stated that only two cases thus far have been reported in literature. It is probable that the child will be presented before the Society at a future meeting.

Exhibition of the "Koch comma bacillus of Asiatic cholera," by Dr. L. L. McArthur.-The speaker addressed the Society orally, during which he stated that Koch had devoted more time and study to the solution of the cholera problem than any other physician, and from the fact that he has so far established his cholera theory over all opposing ones, and successfully met all arguments, no little interest in the subject is felt by the people of this country, inasmuch as cholera may cross the ocean during the coming summer. The comma bacillus of Asiatic cholera is distinguished only when magnified about a thousand times (to $r, 600$ times). They can be taken into the stomach with water, and although very few may be swallowed, their power of reproduction is so wonderful that in a day the victim will be suffering the agonies of a fully developed case. The disease, the speaker continued, is said to be the irritation in the stomach and alimentary tract caused by the presence of these pests. The water in the blood is lost, and if the disease is not checked or arrested death ensues. The germs pass from the victim and, by going through the sewers and down the rivers, cause the disease and death to the people living along the streams. The germs may also be carried in the air, or in the clothing. Moisture is an essential condition for their reproduction or life. If they are placed in a warm, dry place, they will die in a few weeks' time. Koch, in his experiments, carried this comma bacillus through forty cultivations or generations, and the last cultivation, introduced into the stomach of a dog, brought on cholera Asiatica, and death resulted in three days.

The bacilli exhibited were received from Koch's laboratory but a few days ago, and were sent by Dr. Odo Betz, from Tübingen, Grermany, to Dr. Doering, of this city, and are the first ever exhibited in Chicago.

A number of the members participated in an informal discussion of cholera Asiatica and cholera nostra, and the specimens were closely examined.

The Society then adjourned.

$$
\text { Liston H. Montgomery. }
$$

\section{STATE MEDICINE.}

\section{To His Excellency Governor Jackson.}

Dear Sir: The fear which I expressed to you many weeks ago, that I should not be able, because of my poor health, to continue in the service of the 
state to the end of my official term (1888), I find, to my inexpressible sorrow, fully realized much sooner than I had expected. I am, therefore, compelled to lay down the office with its honors which you conferred upon me in June, I88I, and beg that you will accept my resignation to take effect Monday, the $23 \mathrm{~d}$ inst., at $\mathrm{I} 2$ o'clock $\mathrm{M}$.

Let me tell you truly that I can find no words to fitly express my regret that I am compelled to retire from the State Board of Health, for God knows how earnestly my whole heart has been engaged in the work.

From the date of the organization of the Board to the present, my association with my colleagues has been a source of continued pleasure; and from Your Excellency I have received many kindnesses which greatly encouraged my labors, and for which I shall never forget to feel grateful. Indeed, I am under many and lasting obligations to the officers of each department of the state government for courteous acts.

Finally, need I assure you of my continued interest in the cause of the public health ?-in the higher and higher standard of the medical profession within our borders?-and in West Virginia's prominence in the cultivation of sanitary science? All these are too near my heart to be neglected or forgotten. Believe me, Very truly yours,

JAMES E. REEVES.

State of Wlist Vikginia,

Executive Dei'artment,

WhEeling, Feb. I8, I 885

James E. Reeves, M.D., Secretary State Board of Health, Wheeling, W. Va.

Dear Sir: I am in receipt of your communication, of date the $5^{\text {th }}$ instant, requesting the acceptance of your resignation as a member of the State Board of Health, to take effect on Monday, the $23 \mathrm{~d}$ instant, at I 2 o'clock, M.

I greatly regret that the condition of your health compels you take this step. You have been identified with the Board from its organization until the present time. Its objects have been not only, by investigation and proper action based thereon, to promote the public health, but also to elevate the standard of the medical profession in the state. To these objects I am aware you have devoted a large share of your valuable time, aided by a ripe experience in medical and sanitary science. Your labors, in conjunction with the other members of the Board, have raised the standard of the profession to a higher plane than before attained by it, and through the operation of our health laws placed the state on advanced ground in the development of sanitary science.

I had hoped that your valuable services would have been continued, at least until the end of your term, and until this department of the state's service had become so firmly established as not to be endangered by the loss of so efficient an officer.

In accepting your resignation, it is with the hope that your health may be speedily restored, and that you may from time to time, by your counsel, aid the Board in carrying forward the great work for which it was created, so that the objects which you have had so much at heart may be fully realized and result in lasting good to the people of West Virginia.

With the highest regard, and my best wishes for your future health and happiness, I am

\section{Very truly yours,}

J. B. JACKSON.

\section{FOREIGN CORRESPONDENCE.}

\section{LONDON LETTER.}

LONDON, Feb. I 885 .

At a meeting, convened by the Vegetarian Society and held in Exeter Hall, the chairman said they had served $16 \mathbf{I}, 000$ meals during the late International Health Exhibition, or an average of about 910 per day; after paying rent and all expenses they were in a position to return the guarantee fund subscribed by their friends in aid of the experiment, and there remained a balance of over £Ioo, besides their crockery, tables and cooking utensils. The money balance, in accordance with the public undertaking of the Society, was being spent in vegetarian meals for the poor in several large towns. Miss Anna Kingsford, M.D., protested against the representations of those who seemed to think that vegetarians wished to send men out like Nebuchadnezzar to graze, to make them eat cabbages in the morning and grass in the evening. She maintained, however, that men were classed anatomically and physiologically with the apes, whose teeth were not flesh-tearing teeth. The apes used their teeth for cracking. nuts, and never for masticating mutton chops or eating saddle of mutton. Flesh-eaters were liable to many diseases from which vegetarians were free. She had cured herself of tubercular consumption by living on vegetable food. Having been told that she had not six months to live, and that she must eat raw meat and drink port wine, she had gone into the country and tried cold porridge and fruit, and was there that day on that piatform. She had found the shoemaker to make her shoes without leather, and she assured her audience that they did equally well for the muddy streets of London and for climbing the hills of Switzerland.

During the past month the annual treats have taken place at most of the metropolitan hospitals. A pathetically interesting scene was witnessed at King's College Hospital. The resident medical officers, with the aid of sisters, nurses, students and others, had designed an evening's entertainment for the patients. All the wards were pleasingly decorated and illuminated with Japanese lanterns. A Christmas tree was set up in the great hall, which itself was brilliantly illuminated and decorated. A stage was here erected for the purpose of an entertainment devised by the medical officers, and from the various staircase landings those patients who could bear removal from the wards watched with keen interest the performance below. Many of the sick people could only watch the entertainment in a recumbent position, and were carried on their mattresses to their 